\title{
Association of severe myoclonic epilepsy of infancy (SMEI) with probable autoimmune lymphoproliferative syndrome-variant
}

\author{
Associazione di epilessia mioclonica severa (SMEI) con una probabile syndrome autoimmune linfoproliferativa-variante
}

\author{
A. Berio, ${ }^{1}$ G. Mangiante, ${ }^{1}$ A. Piazzi ${ }^{1}$
}

Key words: severe myoclonic epilepsy of infancy, autoimmune lymphoproliferative syndrome, voltage-gated sodium channels, linear IgA disease

\begin{abstract}
The paper reported on a case of severe myoclonic epilepsy of infancy (SMEI) associated with a probable autoimmune lymphoproliferative syndrome variant (Dianzani autoimmune lymphoproliferative disease) (DALD).

A male patient with typical features of SMEI and a SCN1A gene variant presented in the first year of life with multiple lymph nodes, palpable liver at $2 \mathrm{~cm}$ from the costal margin, neutropenia, dysgammaglobulinemia, relative and sometimes absolute lymphocytosis. Subsequently the patient presented with constantly raised IgA in serum and positive antinuclear and thyroid antimicrosomal antibodies.

The diagnosis of probable autoimmune lymphoproliferative syndrome was made; arthritis, skin and throat blisters, which appeared subsequently led to the diagnosis of linear IgA disease. On the basis of these unique associations, the Authors hypothesized that autoimmunity may be partly responsible of the severe epileptic symptomatology, perhaps mediated by autoantibodies against sodium channels or by accompanying cytotoxic T-lymphocytes. Corticosteroid treatment ameliorated the epilepsy and laboratory tests.

Future studies will be necessary to evaluate the relevance of autoimmunity in SMEI.
\end{abstract}

Pediatric Chair, Department of Pediatric Sciences "G. De Toni”, University of Genoa, Genoa, Italy

Indirizzo per la corrispondenza (Corresponding author):

Prof. Agostino Berio,

Director of Pediatric Chair, Department of Pediatric Sciences, University of Genoa

Largo G. Gaslini 5, Genoa (Italy).

E-mail: agostino.berio@unige.it

\section{Riassunto}

Gli Autori riportano un paziente con epilessia mioclonica severa dell'infanzia (SMEI) ed una variante del gene SCN1A, associata con una probabile sindrome autoimmune linfoproliferativa, (variante malattia autoimmune linfoproliferativa di Dianzani).

Un paziente con il quadro clinico tipico della SMEI, presentò nel primo anno di vita multipli linfonodi, margine epatico palpabile a $2 \mathrm{~cm}$ dall'arco costale, neutropenia, disgammaglobulinemia, linfocitosi relativa e talvolta assoluta. Successivamente il paziente presentò IgA nel siero costantemente elevate ed anticorpi antinucleo ed antimicrosomi tiroidei positivi.

Fu posta diagnosi di probabile variante della sindrome autoimmune linfoproliferativa (DALD); la comparsa di artrite, vescicole cutanee ed in faringe, che apparvero successivamente, portarono alla diagnosi di possibile malattia lineare ad IgA.

Sulla base di queste associazioni, segnalate per la prima volta, gli Autori hanno ipotizzato che, oltre alla turba genetica, l'autoimmunità possa essere in parte responsabile della grave sintomatologia epilettica, forse mediata da autoanticorpi contro i canali del sodio o da T-linfociti citotossici. Il trattamento con cortisone migliorò il quadro epilettico, clinico e di laboratorio.

Ulteriori studi diranno se è consigliabile ricercare sistematicamente la presenza di autoimmunità in ogni caso di SMEI.

\section{Introduzione}

Severe myoclonic epilepsy of infancy (SMEI or Dravet syndrome) is one of the most severe forms of generalized epilepsy. ${ }^{1-2}$ This form is frequently associated with SCN 1A gene mutations, ${ }^{3}$ but factors modulating gene expression in phenotypes are not known yet. ${ }^{4}$ We report on a case of severe myoclonic epilepsy of infancy associated with a probable autoimmune lymphoproliferative syndrome. ${ }^{5,6,7}$ 
The proband is a male now 38 years old. The maternal grandmother presented with lupus erythematoides; the paternal lineage included some persons with febrile convulsions. The mother presented with arthritis, dysgammaglobulinemia (low IgA, raised $\operatorname{Ig} G$ ), mild anemia, weakly positive Coombs test, peripheral lymphocytosis, normal $\mathrm{B}$ and $\mathrm{T}$ lymphocytes and $\mathrm{CD}+4 / \mathrm{CD}+8 \mathrm{~T}$ cell ratio.

In the first months of life, the proband showed enteritic manifestations. At 3 and 5 months of life, he received Di-Te-Per polio vaccins. The patient presented normal development until 7 months of age when he complained of left febrile tonic-clonic hemiconvulsions, which occurred again at 9 and at 12 months of age, as afebrile, alternating hemiconvulsions, mainly of clonic type, and an episode of convulsive status epilepticus. Phenobarbital therapy was started. EEG, initially normal, showed slow waves at 9 months of age.

At 1 year of life, multiple lymph nodes $1-2 \mathrm{~cm}$ in size were present, the liver was palpable at $1-2 \mathrm{~cm}$ from the costal margin, the spleen was not palpable. The patient presented $11010 / \mathrm{mm} 3$ white blood cells, lymphocytosis, neutropenia (table 1), Hb $12.1 \mathrm{~g} / \mathrm{dl}$; protein, albumin and aminoacid serum levels, ECG and fundus oculi were normal; globulins were low.

The epileptic symptomatology worsened in the second year of age with numerous seizures of multiple type occurring every day: febrile and afebrile generalized tonic-clonic, clonic, atonic, and atypical absences.

EEG showed multifocal and generalized epileptic discharges and a hypsarrythmic-like episode, treated by an ACTH cycle $(3 \mathrm{mg} / \mathrm{Kg} /$ day for 20 days) without any amelioration. Basal GH, insulin, leucine, glucagone, and tolbutamine tests were normal; fasting hypoglycaemia was present; Ig were diminished on electrophoresis. Development, initially normal, slowed from this age. The patient complained of frequent myoclonic seizures affecting his arms and of unilateral or generalized clonic seizures at the age of 3 years. Interictal EEG recorded generalized epileptic discharges (and a background of slow waves -theta waves.

Dysgammaglobulinemia with diminished $\operatorname{IgG}$, IgA, IgM in serum and predominant lymphocytes compared to neutrophils were reported. Myoclonus of legs and arms (recorded during polygraphic monitoring), many seizures of various type resistant to different therapies (Phenobarbital, benzodiazepines, sodium valproate) were reported in subsequent years. CT was normal. On EEG, bilateral parieto-occipital polyspikes and waves were stimulated by light.On the basis of clinical and EEG findings, at 5 years of age, severe myoclonic epilepsy of infancy (SMEI) was diagnosed.

During subsequent controls, hypotonia, eczema, raised SGOT and SGPT [respectively, 50 (nv<35), 49 UL/v.n<45]; low IgG and IgM, raised IgA (table 2), normal B lymphocytes and rosette forming $\mathrm{T}$ lymphocytes, normal phytohemagglutinin test were observed. At 8 years of age, IgG and IgM were low, IgA were persistently high. A cycle of immunoglobulins $(30 \mathrm{mg} / \mathrm{Kg} /$ day i.m. every 3 weeks for 6 months) was ineffective on the epileptic symptomatology, which continued unchanged until 21 years of age, when seizures became worse, and dysphagia, ataxia, hyperreflexia on the right side were reported. MRI showed slight cortical atrophy; laboratory test demonstrated positivity for ANA (I:20), antimicrosomal antibodies (I:40), circulating immunocomplexes $(13 \%$; nv<4), low T4 $(0.87$ $\mathrm{ng} / \mathrm{dl}$; nv 0.93-1.86) and raised TSH (4.5 microU/ml, nv0.25-3.1). EEG showed slowing of the background activity. Diagnosis of autoimmune thyroiditis with hypothyroidism was made. Bilateral leg pain, hyperreflexia and raised nerve latency on EMG (tibialis posterior nerve) led to the diagnosis of peripheral neuropathy. WBC, neutrophils and platelets appeared normal, with high lymphocyte rate from the age of 21 to 26 years of life, when arthritis, positive ANA (I:160), high CRP $(8.5-3$; nv $<0.5)$, weakly positive $\mathrm{HCV}$ antibodies were reported and, on the basis of clinical and laboratory symptomatology, the patient started cortisone therapy (at 28 years, 9 months of age).

Subsequently, lymphocyte subpopulations were normal (tab. 3). An episode of skin blisters, throat pain, arthritis with high IgA in serum, slightly elevated CRP, positive ANA (1:16-1: 640) with granular pattern, low $\mathrm{C} 3$ and $\mathrm{C} 4$ and negative ENA occurred and linear IgA disease was suspected; cardiolipins, anti-neutrophil, anti $\mathrm{GAD}$, anti-islets cell, anti-adrenal, anti-gluten, anti-gastric mucosa antibodies were negative. Screening of the SCN1A gene showed a nucleotide splice site variant IVS $1+5 \mathrm{G} / \mathrm{A}$ in intron 1 , not present in parents.

On the basis of clinical and laboratory data, SMEI and associated autoimmune disease with suspected lymphoprolipherative syndrome ${ }^{5,6,7}$ was diagnosed. With continued cortisone therapy (0.5-1 $\mathrm{mg} / \mathrm{Kg} /$ day), the seizures gradually diminished to one every week, EEG showed diffuse delta waves (aspecific alterations), $C D+4$ were slightly elevated, $\mathrm{B}$ lymphocytes, $\mathrm{CD}+8$ and $\mathrm{CD} 4+\mathrm{CD} 8+$ ratio were normal (table 3), a condition compatible with autoimmunity, and CD-4, CD-8 T cells were normal. An episode of swelling of left cervical tissue with 2 palpable parotid lymphnodes, and fibrotic on echography, disappeared and skin blisters and arthritis ameliorated by cortisone; on echography liver and spleen were normal. Serum IgA remained high, while thyroid function, and anti-thyroideal antibodies normalized, ANA were borderline positive (1:80). Moderate disability was present.

\section{Discussion}

Our patient was affected by epilepsy, and a haematological and immunological disorder. He presented with symptoms of SMEI (Dravet syndrome) ${ }^{1,2}$ appearing in the first year of life, including multiple seizures, myoclonus, ataxia, and mild mental retardation. EEG was initially normal, but then showed generalized spikes and waves and other different records EEG features. A nucleotide variant of SCN1A gene was present. SMEI was recently recognized in the pediatric epileptic population after the discovery of a mutation in the neural sodium channel alpha 1 subunit gene SCN1A (a gene which produces the Nav 1.1 protein forming the transmembrane pore) in $80 \%$ of patients ${ }^{3,4,8,9}$; other gene abnormalities were associated. Dravet syndrome is a voltage-gated channel disease. This condition is characterized by onset at approximately 6 months of 
age of febrile or afebrile hemiconvulsions or convulsions, initial normal development and EEG, then, in the second year of life, myoclonus of limbs and eyes and multiple seizures (clonic, generalized tonic-clonic, complex partial), absence or generalized status epilepticus. The EEG is initially normal, but interictal activity is recorded with disease progression (generalized spikes and waves, focal/multifocal EEG abnormalities).

The syndrome may be recognized also in adulthood on the basis of epileptic symptomatology, including generalized tonic-clonic seizures often present during the night, myoclonus, and convulsions of different type. ${ }^{9-10}$ Cerebellar ataxia, spasticity, or extrapyramidal dystonia are often present, appearing at variable ages. The patient is mildly or severely retarded with poor intellectual development after the first year of life. ${ }^{10}$ Most of these symptoms are present in our patient. SCN 1A gene is located on the long arm of chromosome 2, in a cluster of voltage-gated sodium channel genes. ${ }^{4}$ In SCN 1Arelated diseases, mutations are spread throughout the gene and are of different type (deletions, transitions, missense, nonsense, frameshift, and splice-site mutations, that alter DNA transcription or RNA for translation). In $95 \%$ of cases, they are "de novo" mutations. ${ }^{10}$

The variant present in our case (i.e.IVS $1+5 \mathrm{G} \rightarrow \mathrm{A},{ }^{11}$ now named Int $\left.1+\mathrm{G} 5 \mathrm{~A}^{12}\right)$ is an intronic epilepsy-associated mutation of the voltage-gated sodium channel $\mathrm{Na} 1.1$, reported in the catalog of SCN $1 \mathrm{~A}$ variants. ${ }^{12}$

Today, splicing variability is the core problem of SCN 1A. It is now accepted that intronic gene regulation and post-transcriptional alteration (e.g. variable splicing) have a high potential for functional diversification. ${ }^{12}$ It is unknown whether moderate or simple genetic variations impact on splicing and if such changes contribute to the pool of truncation mutations, with consequent lack of $\mathrm{Nav}$ 1.1 and severe SMEI. ${ }^{12}$

Clinically, mutations of SCN1A gene, associated with epileptic syndromes, span a continuum of gravity from SMEI (severe) to genetic generalized epilepsy with febrile seizures plus (GEFS+) (relatively mild). ${ }^{13}$

In SMEI patients, between 2 and 8 years of life, status epilepticus is common and seizure severity reaches a peak, a condition attributed to $\mathrm{Na}_{\mathrm{v}} 1.1$ sodium channel abnormal expression, appearing at this age, when sodium channel $\mathrm{Na}_{\mathrm{v}} 1.1$ protein should reach the normal level. ${ }^{13}$ Triggers for status epilepticus in SMEI are intercurrent infections and slight increases in body or ambient temperature. ${ }^{13,14}$ In SMEI, hot bath, fever, and physical exercise may induce seizures by reducing seizure threshold temperature, as also shown by experimental data in SMEI mice with heterozygous deletion of $\mathrm{Na}_{\mathrm{v}} 1.1$ voltage-gated sodium channel. ${ }^{13}$ However, it was affirmed that differences in SMEI and GEFS+ are not ascribable exclusively to differences in channel behavior. ${ }^{15}$

It was demonstrated that inflammatory/immunological factors may contribute to the pathogenesis of seizures in some forms of epilepsy. ${ }^{16}$ In febrile seizures, a relationship between immune-inflammatory mediators (especially IL-1 $\beta$ and IL 1ra system) and epileptogenesis was proposed. ${ }^{14,17}$ In this condition, the CNS is the target of an immune-inflammatory response, beginning in the peripheral lymphoid system. ${ }^{17}$ In humans, it was postulated that enhanced production of IL $1 \beta$ after an immune challenge ${ }^{18}$ may recruit cells of the adaptive and innate systems perpetuating the inflammation, ${ }^{17}$ and, by decreasing seizure threshold, may induce easy excitatory

\begin{tabular}{|c|c|c|c|c|c|c|c|c|c|c|c|c|c|}
\hline Table 1 & & & & & & & & & & & & & \\
\hline Age, Years & $1 y$ & $2 y 6 m$ & 3 & $7 y 7 m$ & 21 & 25 & 26 & $28 \mathrm{y} 6 \mathrm{~m}$ & $28 \mathrm{y} 9 \mathrm{~m}$ & 29 & 34 & $35 \mathrm{y} 6 \mathrm{~m}$ & 38 \\
\hline $\mathrm{WBC} / \mathrm{mm} 3$ & 11010 & 6400 & 6200 & 6900 & 6984 & 5380 & 7080 & 7260 & 7130 & 6650 & 6290 & 6450 & \\
\hline $\mathrm{N} \%$ & $\begin{array}{c}5 \\
\text { ac } 550\end{array}$ & 40 & 16 & 29 & 33 & 28 & 32 & 29.7 & 30.5 & 23.6 & 29.8 & 37.1 & 52 \\
\hline$L \%$ & $\mathrm{Ac}+10129 / \mathrm{mm} 3$ & 55 & 82 & 65 & 52 & 59 & 52 & 59.2 & 58.3 & 62 & 57 & 51.3 & 36 \\
\hline
\end{tabular}

Ac+ = absolute count

\begin{tabular}{|c|c|c|c|c|c|c|c|c|c|c|}
\hline Table 2 & & & & & & & & & & \\
\hline Age, Years & $1 y$ & $2 y 6 m$ & $3 y$ & $7 y 7 m$ & $8 y 7 m$ & $10 y 7 m$ & $11 y$ & $21 y$ & $23 y$ & $25 y$ \\
\hline Prot.g & $6 \%$ & 6.45 & 5.7 & & & & & & & \\
\hline$\gamma$ glob. & $6 \%$ & $10 \%$ & $7.9 \%$ & & & & & & & \\
\hline $\operatorname{lgG}$ mg/dl (NV) & & immunoelectrophoresis & $\downarrow$ & $\begin{array}{c}700 \\
(800-1800) \\
\end{array}$ & $\begin{array}{c}393 \\
(730-1410) \\
\end{array}$ & $\begin{array}{c}730 \\
(650-1450) \\
\end{array}$ & 500 & $\mathrm{~N}$ & $\mathrm{~N}$ & $\begin{array}{c}1003 \\
(700-1600) \\
\end{array}$ \\
\hline $\operatorname{lgA}$ mg/dl (NV) & & immunoelectrophoresis & $\downarrow$ & $\begin{array}{c}360 \\
(120-260)\end{array}$ & $\begin{array}{c}331 \\
(74-260)\end{array}$ & $\begin{array}{c}375 \\
(60-200)\end{array}$ & 300 & $\begin{array}{c}623 \\
(90-450)\end{array}$ & $\begin{array}{c}692 \\
(90-450)\end{array}$ & 788 \\
\hline lgM mg/dl (NV) & & immunoelectrophoresis & $\downarrow$ & $\begin{array}{c}65 \\
(80-170)\end{array}$ & $\begin{array}{c}30.6 \\
(68-175)\end{array}$ & $\begin{array}{c}55 \\
(50-215)\end{array}$ & 60 & $\mathrm{~N}$ & $\mathrm{~N}$ & $\begin{array}{c}121 \\
(40-230)\end{array}$ \\
\hline
\end{tabular}


neurotransmission and evoke febrile convulsions contributing to some disorders such as SMEI and GEFS ${ }^{+18}$ often clinically beginning with febrile convulsions.

On the basis of experimental results, Ravizza et al. ${ }^{16}$ showed that some specific inflammatory processes as status epilepticus (common in SMEI), initiated in the brain by a trigger factor, stimulate epileptogenesis (i.e. a latency phase of $\geq 1$ week devoid of seizures but prodromal to the beginning of epilepsy). Vezzani et al. ${ }^{17}$ demonstrated that inflammation of the brain is a chronic process persisting in the epileptogenic tissue which may contribute to the pathogenesis of seizures. ${ }^{17} \mathrm{~A}$ chronic up-regulation of IL $1 \beta$ and 1RI system in microglia and astrocytes, increasing neuronal excitability, precedes the onset of epilepsy and is present after seizures. The recurrence of spontaneous seizures can contribute to maintain inflammation. ${ }^{16,17}$ In this condition, cytokines with pro-inflammatory action (mainly IL 1B) have a pre-excitatory effect, triggering a cascade of events which results in altered transcription of genes that may contribute to changes in ion channels during the epileptogenic process. ${ }^{17}$

For some authors, SMEI may be a useful model to understand the role of inflammation in epileptogenesis. In our patient, if the intronic mutation actually cause an abnormal voltage-gated channel protein, this could have impacted directly on the function of the channels, with consequent epilepsy. Alternatively, the mutated protein could have been immunogenic, causing autoimmunity against the voltage-gated channel.

In our case, also immunological disorders were present. WBC was normal. At 1 year of life neutropenia was present, disappearing at 21 years of age.

Lymphocytes were higher than neutrophils at all ages and were the predominating cells, as in two cases reported by Canale-Smith. ${ }^{5}$ At 29 years of life, $\mathrm{T}$ and $\mathrm{B}$ lymphocytes presented a normal ratio during cortisone therapy. $\mathrm{CD}^{+}$and $\mathrm{CD} 8{ }^{+}$and $\mathrm{CD} 4-$ and $\mathrm{CD} 8-\mathrm{T}$ lymphocytes were normal. $\mathrm{Hb}$ protein and albumin in blood were normal. IgG were low until 8 years of life, then normalized. At 8 years of life, i.m. IgG were administered. From 7 years of age to adulthood, IgA were constantly high. ESR and CRB ranged from normal to high values.

In our case, the disease was characterized by presence of fever only in case of bacterial infections. Autoimmunity following an intermittent/remitting pattern was signalled by the presence of thyroid

\begin{tabular}{ccccc}
$25 y 2 m$ & $25 y 8 m$ & $26 y$ & $30 y$ & $38 y$ \\
\hline $\begin{array}{c}888 \\
(700-1600)\end{array}$ & $\begin{array}{c}874 \\
(700-1600)\end{array}$ & $\begin{array}{c}752 \\
(700-1100)\end{array}$ & $\begin{array}{c}904 \\
(700-1600)\end{array}$ & $\begin{array}{c}756 \\
(700-1600)\end{array}$ \\
608 & $\begin{array}{c}614 \\
(70-400)\end{array}$ & 562 & 666 & 573 \\
$\begin{array}{c}155 \\
125\end{array}$ & $\begin{array}{c}122 \\
(40-250)\end{array}$ & $\begin{array}{c}166 \\
(40-230)\end{array}$ & $\begin{array}{c}164 \\
(40-230)\end{array}$ \\
\hline
\end{tabular}

antimicrosomal and anti-nuclear antibodies. A pathological endocrinological condition was shown by hypothyroidism.

The association of haematological and immunological conditions with autoimmunity led to differential diagnosis between lymphoproliferative diseases and other pathological conditions.

The presence of hyper IgA and of autoantibodies in blood led us to postulate that the patient's condition had a primary immunological basis. The association among lymphadenopathy, polyclonal hypergammaglobulinemia, and circulating autoantibodies is typical of the autoimmune lymphoproliferative syndrome..$^{5-6-7}$

It is now accepted that a syndrome characterized by autoimmunity and lymphoproliferation may be due to many different genetic ${ }^{19,20,21}$ or environmental factors. In most cases, it is due to FAS deficiency (ALPS type 1a), a disease inherited in an autosomal dominant manner, due to mutations in the TNFRSF 6 gene of FAS. Bcell lymphocytosis, hypergammaglobulinemia, and auto-antibody production are prominent features of ALPS $^{6}$ that point to a severe dysregulation of humoral immunity. In the genetic condition described by Canale and Smith ${ }^{5}$ (1967), this syndrome appears in early childhood and has a high degree of clinical expression variability, as it presents with lymphadenopathy, hepatomegaly or splenomegaly or both, hypergammaglobulinemia, autoimmune cytopenias (neutropenia, anemia, and/or thrombocytopenia), lymphocytosis, circulating autoantibodies (antinuclear, anti-red blood cells), positivity of RA and Coombs tests and other inflammatory tests. ${ }^{5-6-7}$ Cutaneous manifestations (eczema ${ }^{22}$ ), polyneuropathy, raised CD4, CD8-T cells $(\mathrm{nv}<1 \%)^{7}$ were subsequently reported. Asymptomatic individuals with FAS mutations may show a much lower increase in CD4-CD8 T cells compared to ALPS patients and the proportion of double negative $\mathrm{T}$ cells remains $<0.5 \% .{ }^{23}$ The syndrome is responsive to cortisone therapy. In a case, as suspected in our patient, ALPS was associated with linear disease, an autoimmune subepithelial disorder characterized, at all ages from the first month of life, by onset of blisters on skin and mucosal membranes, pain and swallowing difficulties, raised serum IgA, and linear IgA deposits at the basement membrane zone. ${ }^{24}$

Wu et $\mathrm{a}^{25}$ reported on a case of lupus and lymphoproliferative disease, due to a FAS-ligand gene mutation and consequent FAS-ligand deficiency, with positive lupus test, raised T-cells after activation, normal CD4- CD8- T cells in blood (ALPS type 1b).

Dianzani et $\mathrm{a}^{26}$ reported on a series of male patients with a familial syndrome characterized by thrombocytopenia, enlarged lymph nodes and/or splenomegaly, neutropenia in which TCD4- and TCD8- cells were not expanded, PHA test was normal as in controls, and hyper $\gamma$-globulinemia ( 2 cases), hypo- $\gamma$-globulinemia $(2$ cases), and $\gamma$-globulinemia fluctuations (3) were present. ANA were present in 3 cases, while no FAS nor FAS-ligand mutations were demonstrated, but relative resistance to programmed cell death induced by monoclonal antibodies to FAS was present. This condition was normalized by methylprednisolone; family history of the patients suggested the diagnosis of a genetic disease, that the authors named "autoimmune lymphoproliferative disease". (ALPS III or ALPS due to unknown defect ${ }^{21,23}$ ). ALPS II may be due to a 
deficit of caspase 10 , characterized by a very large number of CD4CD8- $\mathrm{T}$ cells ${ }^{27}$, or of caspase 8 (without autoimmunity). ${ }^{28}$

Today ALPS is considered a consequence of defective lymphocyte apoptosis associated with mutations of the FAS gene (ALPS-FAS) or of the FAS ligand (ALPS-FASL) gene or of signalling molecules as Caspase 10 (ALPS-CASP 10). Genetically undetermined ALPS was called ALPSU; a phenotypic variant of ALPS was named Dianzani's autoimmune lymphoproliferative disease (DALD). . $9,30,31^{2}$ DALD patients present with the same clinical symptomatology as ALPS but do not show an increase in double negative $T$ cells and no molecular cause of the disease has been reported even if $\mathrm{T}$ lymphocytes are resistant to FAS-induced apoptosis.

In our case, familyal history and dysgammaglobulinemia in the mother, patient's clinical features (palpable lymph nodes, mild hepatomegaly in infancy), eczema, laboratory data (fluctuating $\operatorname{IgG}$, raised IgA, constant prevalent proportion of lymphocytes, low neutrophils, antinuclear and antithyroid antibodies, anti-HCV antibodies, slightly raised B-cell count at 28 years of life normalized with cortisone, positive inflammatory tests) suggest the diagnosis of an autoimmune lymphoproliferative disorder, responding to cortisone (probable autoimmune lymphoproliferative syndrome, DALD variant).

Whatever the classification of our patient may be, the symptoms led to a diagnosis of dysregulation of the humoral immunity that may worsen the symptoms of an independent, likely genetic disease (Dravet syndrome). A similar condition was also reported in a mitochondrial disease (Kearns-Sayre syndrome) with thyroiditis and Hashimoto encephalopathy. ${ }^{32}$

DALD patients may have an abnormality involving FAS signalling pathway at different levels, downstream from the receptor. ${ }^{26}$ Families of DALD patients present with high frequency of autoimmune diseases with both autoantibodies and $\mathrm{T}$ cell-mediated disease. DALD is genetically heterogeneous: different patients may carry diverse mutations at different levels of the FAS signalling pathway and a second mutation was suggested as the cause of the disease [the patients were sensitive to alternate cell way mediated by corticosteroids]. Alternatively ALPS and DALD could be consequent to a different genetic defect, impairing a common biochemical pathway. ${ }^{33}$ Some complementary factors are required for the development of the disease; gene variability and particular polymorphisms encoding osteopontin, perforin, SH20 may predispose to ALPS and DALD. ${ }^{34,35}$

ALPS and DALD patients present with high serum levels of osteopontin (OPN), a glicoprotein produced by activated cells, and of tissue inhibitor of metalloproteinase-1 (TIMP-1), which in vitro inhibits lymphocyte apoptosis. ${ }^{33,36}$

OPN, a proinflammatory cytokine, promotes the development of Th 17 (T Helper 17) cells, secreting interleukin 17F and 17A, able to inhibit in vitro FAS-induced cell death in FAS-sensitive T cells and to facilitate the development of autoimmunity, ${ }^{36}$ OPN potentiate in $\mathrm{T}$ cells the lymphoproliferation, IFN $\gamma$ production, and $\mathrm{CD}$ 40 expression which stimulates B cell proliferation. ${ }^{34,35}$ In sera of ALPS and DALD patients, IL17A and IL17F present increased levels and favor $T$ cell lymphoproliferation. IL-1ß, which supports the production of pro-inflammatory IL-17, presents higher levels in ALPS and DALD patients than in controls. ${ }^{37}$ The same cytokines may have a role in the pathogenesis of SMEI. ${ }^{17}$

Perforin expressed in CTL (cytotoxic T cells) and NK cells is involved in cell-mediated cytotoxicity. ${ }^{38}$ In subjects with defective FAS function, heterozygous variants of Perforin gene (PRF) decreasing the function may act as possible factors causing ALPS and DALD development ${ }^{39}$ and may influence the apoptotic defect in these diseases. UNC 13D gene variants also exert a modifying effect on FAS-inherited function and are risk factors of DALD. In our patient, additional environmental factors may have interfered with $\mathrm{T}$ cell apoptosis. HCV core protein, which likely targets multiple pathways involved in apoptosis, ${ }^{40}$ may have inhibited TNFó-induced apoptosis, modifying interleukin

\begin{tabular}{|c|c|c|c|c|c|c|c|}
\hline \multicolumn{8}{|l|}{ Table 3} \\
\hline & \multicolumn{3}{|c|}{29 years (cortisone therapy) } & \multicolumn{3}{|c|}{35 years 6 months (cortisone therapy) } & \multirow{2}{*}{$\begin{array}{c}36 \text { years (cortisone therapy) } \\
\%\end{array}$} \\
\hline & $\begin{array}{c}\% \\
\text { of WBC }\end{array}$ & $\begin{array}{c}\% \\
\text { of Lymphocytes }\end{array}$ & $\begin{array}{l}\text { Absolute } \\
\text { value }\end{array}$ & $\begin{array}{c}\% \\
\text { of WBC }\end{array}$ & $\begin{array}{c}\% \\
\text { of Lymphocytes }\end{array}$ & $\begin{array}{c}\text { Absolute } \\
\text { Count }\end{array}$ & \\
\hline$\overline{\mathrm{WBC} / \mathrm{mm} 3}$ & & & 7100 & & & 6450 & \\
\hline Peripheral Lymphocytes CD+45 & 61.9 & & 4395 & 51.3 & & 3310 & \\
\hline \multicolumn{8}{|l|}{ T Lymphocytes } \\
\hline $\mathrm{CD}+3 \mathrm{CD}+45$ & & $\begin{array}{c}79 \\
(55-84)\end{array}$ & $\begin{array}{c}3471 \\
(690-2540)\end{array}$ & & $\begin{array}{c}77 \\
(55-84)\end{array}$ & $\begin{array}{c}2533 \\
(690-2540)\end{array}$ & $\begin{array}{l}\text { 78.3 of Lymphocytes } \\
\text { TCR } \alpha+70.1 \% \text { of Lymphocytes } \\
\text { TCR } \alpha+\text { CD4- CD8- } 0.4 \text { of Lymphocytes } \\
\text { TCR } \gamma \delta+0.7 \% \text { of Lymphocytes } \\
\text { TCR } \gamma \delta+\text { CD4- CD8- } 0.4 \% \text { of ymphocytes }\end{array}$ \\
\hline T Helper CD+3 CD+4 & & $\begin{array}{c}59 \\
(31-60)\end{array}$ & $\begin{array}{c}2607 \\
(410-1590)\end{array}$ & & $\begin{array}{c}59 \\
(31-60)\end{array}$ & $\begin{array}{c}1941 \\
(410-1590)\end{array}$ & $78 \%$ of T-lymphocytes \\
\hline T Cytotoxic CD+3 CD+8 & & $\begin{array}{c}22 \\
(13-41)\end{array}$ & $\begin{array}{c}971 \\
(190-1140)\end{array}$ & & $\begin{array}{c}18 \\
(13-41)\end{array}$ & $\begin{array}{c}592 \\
(190-1400)\end{array}$ & 19.1 of T-Lymphocytes \\
\hline B Lymphocytes CD+19 CD+45 & & $\begin{array}{c}16 \\
(6-25)\end{array}$ & $\begin{array}{c}713 \\
(90-660)\end{array}$ & & $\begin{array}{c}13 \\
(6-25)\end{array}$ & $\begin{array}{c}428 \\
(90-560)\end{array}$ & 12.1 of Lymphocytes \\
\hline NK CD-3 CD+16/56 & & $\begin{array}{c}8 \\
(5-27)\end{array}$ & $\begin{array}{c}334 \\
(90-590)\end{array}$ & & $\begin{array}{c}7 \\
(5-27)\end{array}$ & $\begin{array}{c}230 \\
(90-590)\end{array}$ & 4.9 of Lymphocytes \\
\hline T Cytotoxic noMHC Restricted & & $(0-5)$ & & & $\begin{array}{c}3 \\
(0-5)\end{array}$ & 99 & \\
\hline
\end{tabular}


converting enzyme activation and IL-Iß production, with consequent raised lymphoproliferation.

FAS pathway is involved in switching off immune response and cell-mediated cytotoxicity.

In normal subjects, switching off of the immune responses is very important to terminate the proliferation of activated lymphocytes which may damage the normal cells and to avoid cross-reactivity between self and non self. The failure to eliminate apoptotic cells might cause secondary necrosis and inflammatory reaction stimulation, facilitating the presentation of self antigens to the immune system and the development of autoimmunity. ${ }^{31}$ The integrity of lymphocyte apoptosis mechanism is fundamental but may be modified by FAS pathway gene mutations. Other regulators of the immune response belonging to CD28 family (CTLA-4, PDI), whose deficiency has been associated with autoimmunity, are known.

CNS may be the target of auto-immune process and inflammation in ALPS and DALD patients. ${ }^{41,42,43}$ CNS is greatly protected from inflammation by locally circulating $\mathrm{T}$ cells, by some immunosuppressing substances (neurotropins, neurotrasmettitors, TGFß, glycocorticosteroids), and by the FAS-FASL activity of resident cells, mainly astrocytes and endothelial cells. ${ }^{42}$

CNS is highly sensitive to inflammatory damage and the apoptosis of activated immune cells is very important to limit immune cell proliferation due to autoimmune process and inflammation and to decrease the possible tissue damage. Apoptosis of T cells infliltrating the CNS is due to different mechanisms: activation-induced cell death (AICD), perforin-mediated cytotoxicity and FAS/FASL system; ${ }^{42}$ withdrawal of essential growth factors (apoptosis by neglect); glicocorticosteroids (due to ligation of specific receptors, and IL-2 inhibition, and suppression of immune system function) and importantly apoptosis due to FAS-FASL interactions. FAS and FASL, expressed in microglia and astrocytes, regulate inflammation by apoptosis of tissue infiltrating activated FAS-expressing Tcells..$^{43,44}$ FAS and FASL expression is raised in some inflammatory conditions and in astrocytes. FASL expression induces pro-inflammatory cytokine production, apoptosis of surrounding FAS-sensitive cells (neurons, oligodendrocytes), and consequent brain damage. $^{42}$ In our DALD patient with FAS pathway deficiency, FAS/FASL mechanism may have been faulty, with consequent predisposition to CNS inflammation..$^{43}$ Alternatively, FAS pathway deficiency may have predisposed to autoimmunity disease via $\mathrm{T}$ cell-mediated B-cell activation and autoantibodies against CNS neuronal antigen production: ${ }^{43}$ in our patients, B cells were transitorily raised in blood. Other possible mechanisms of proliferating $\mathrm{T}$ cell inactivation could be involved: $\mathrm{T}$ cell-mediated cytotoxicity; induction of apoptosis in activated immune cells; alterated differentiation of TH1/TH2 cells; TGFß, interleukin 10 , and production of other anti-inflammatory cytokines. ${ }^{42}$

The thyroid gland may be the target of autoimmunity in FAS pathway deficiency. In normal subjects, FAS and FASL expressed in CNS and other tissues regulate the inflammatory responses by destruction of tissues infiltrating activated FAS expressing T cells. In thyroiditis, inflammatory infiltration may be induced by antithy- roideal antibodies and $\mathrm{T}$ cells. ${ }^{31,46}$ FAS-positive lymphocytes are present in inflammatory tissues; FAS/FASL in thyroiditis, as consequence of infiltrating inflammatory cell and cytokines, are up regulated in thyrocytes suggesting that FAS-FASL interaction may be responsible of thyroideal cell death. ${ }^{45}$ Defective FAS function was found involved in $20-30 \%$ of autoimmune thyroid diseases and in some other autoimmune diseases (IDDM, MS) and may be ascribed to production of an inherited factor (present also in parents) with negative effect on FAS function. ${ }^{29,42,47}$

The genetically induced FAS pathway deficiency may have predisposed our DALD patient to the development of organ-specific autoimmune autoantibody production and thyroideal disease with possible involvement of cytotoxic mechanisms mediated by FASFASL pathway.

The presence of antimicrosomal antibodies, associated with hypothyroidism, slowing of EEG background activity, diffuse mild brain atrophy, neuropsychological sign, ${ }^{48}$ improved epileptic activity after cortisone, could suggest a direct effect of IgG-mediated antimicrosomal antibodies, possibly due to a common brain-thyroid antigen ${ }^{49,50}$ involving neurons and glia (Hashimoto encephalopathy). ${ }^{32}$ However, the low titre of anti-microsomal antibodies may also demonstrate a unique predisposition to develop multiple antibodies. In normal conditions, the neurons in CNS are protected from brain-reactive antibodies by the blood-brain barrier, but possible breaches in the barrier may permit antibody activity. ${ }^{51}$ It was observed that patients producing one autoantibody have a predisposition to form also other autoantibodies ${ }^{50}$ and that undiscovered antibodies in epilepsy may coexist with not yet identified or irrelevant antibodies. ${ }^{48,50}$ Therefore, some Authors advise to investigate the same target protein for genetic and autoimmune diseases, because similar symptoms may be due to mutation and to autoantibodies targeting the same protein. ${ }^{50}$ In our case, the association of epilepsy with non-organ specific ANA and antimicrosomal organspecific autoantibodies, dysphagia, abnormalities of peripheral sensory-motor nerve conduction, bilateral leg pain and hyperreflexia, atonia, and EMG abnormalities suggest a role of autoantibodies against the $\mathrm{Na}^{+}$ion channels $s^{50,52,53}$ acting on the surface of neurons, with consequent slow inactivation ${ }^{15,54}$ which results in epileptiform activity in mammalian brain ${ }^{52,53}$ and conduction block in peripheral nerve. ${ }^{56}$

The identification of SCN1A mutation involving $\mathrm{Na}^{+}$channels in SMEI and GEFS+ suggests that an autoimmune attack to the mutated $\mathrm{Na}^{+}$channels, recognized as non-self by the organism, may be present in some cases of SMEI, as reported in other epilepsies. ${ }^{50} \mathrm{In}$ this context, CNS should be the target of an immune block of $\mathrm{Na}^{+}$ channels $s^{53}$ or of an immuno-inflammatory reaction involving the neuronal $\mathrm{Na}^{+}$channels (with cytokine, mainly $1 \mathrm{~L}-1 \beta$, production) which started in the peripheral lymphoid system. This condition could also be present in prolonged seizures associated with fever, in status epilepticus ${ }^{16}$ or after systemic infections. ${ }^{17}$ The autoimmunity against $\mathrm{Na}_{\mathrm{v}} 1.1$ channel would slow down channel inactivation ${ }^{15}$ and cause CNS hyperexcitability by lowering neuron inhibition because of reduced function of $\mathrm{Na}_{\mathrm{v}} 1.1$ in inhibitory interneurons ${ }^{57}$ and con- 
sequent seizure induction by hot bath or fever. Alternatively, there can be a production of chronic immuno-inflammatory mediators (IL-1ß, IL 6, TNF 1 $\alpha$ ) with consequent status epilepticus. This condition was recently reported in two ANA-positive patients with voltage gated $\mathrm{K}^{+}$channel autoantibodies and encephalopathy. ${ }^{58} \mathrm{In}$ patients with SCN1A mutations, vaccination is considered a trigger for early onset of SMEI, perhaps via fever induction, ${ }^{59}$ immunomediated mechanism ${ }^{59,60}$ or, in our opinion, stimulation of autoantibody or cytotoxic $\mathrm{T}$ lymphocyte production.

Auto antibody production against neural antigens was supposed in a lymphoproliferative syndrome associated with CNS abnormalities and autism ${ }^{43}$ and demonstrated in Landau-Kleffner syndrome (with seizures, aphasia, and autism), ${ }^{61}$ both responding to cortisone. To our knowledge, the association of SMEI with lymphoproliferative syndrome has not been previously reported. It is possible that, in our case, autoimmunity was a factor interfering with gene expression in this phenotype.

Today, SMEI is considered an epileptic encephalopathy ${ }^{10,14}$, i.e. a disease in which epilepsy is associated with cognitive and motor disorders. It was speculated that severe features of SMEI may be caused by a combination of $\mathrm{Na}^{+}$channel dysfunction with predisposing genetic, developmental, or environmental factors, i.e. that the $\mathrm{Na}^{+}$ channel defect is at the basis of the initial predisposition to seizures but concomitant factors are the immediate cause of the neurological symptoms, which differentiate SMEI from GEFS $+{ }^{15}$ From this point of view, we could hypothesize in our patient the presence of an encephalopathy as a genetic disorder associated with an autoimmune disorder (the lymphoprolipherative syndrome) perhaps aggravating the encephalopathy. ${ }^{62}$ ANA is a non specific antibody but serves as a signal of autoimmunity ${ }^{62}$ and has been associated (as the anti-thyroideal antibody) with encephalopathies which arise in the context of another autoimmune disorder, ${ }^{62}$ either organ-specific (for example thyroid autoimmunity) or non-organ specific (for example lupus erythematosus).

In our patient, ANA and anti-thyroideal antibodies suggest a possible autoimmune pathophysiology of some neurological features. In our opinion, ANA autoantibodies, commonly present in the autoimmune lymphoproliferative syndrome, in our case were not directly responsible of neurological symptoms, but represented a marker of an autoimmune disease, perhaps involving the CNS, mediated by autoantibodies or cytotoxic $\mathrm{T}$ lymphocytes. ${ }^{63}$

In our case, the epileptic symptomatology worsened in autoimmunity, ameliorated concomitantly with regression of clinical autoimmune and inflammatory manifestations, and serum inflammatory indexes normalized during cortisone therapy. This suggests a common autoimmune-inflammatory aetiology and a possible better outcome of cortisone therapy in associated conditions (DALDSMEI), as separately reported for SMEI, ${ }^{1,2}$ ALPS, $^{23}$ DALD $^{26}$ and ALPS associated with Landau-Kneffer syndrome. ${ }^{43}$

In summary, we hypothesize that in our patient with a specific genetic autoimmune disorder (DALD) associated with polymorphism of SCN1A gene (nucleotide splice variant IVS 1+5G/A in intron, anti-thyroideal,ANA, anti hepatitis $\mathrm{C}$ virus), and possibly other autoantibodies (anti antibodies $\mathrm{Na}^{+}$channels antibodies) have interfered with the cerebral function in association with inflammatory factors, aggravating encephalopathy and epilepsy. The amelioration (clinical and immunological) of both these conditions after cortisone therapy could support this hypothesis. Alternatively, the sodium channel dysfunction may have been the unique consequence of the genetic disorder and ANA and antithyroideal antibodies may have been an epiphenomenon or related to antiepileptic drug administration. Further studies are necessary to evaluate the relevance of FAS pathway function in our case of SMEI.

\section{The Authors thanks Anna Capurro for revising the manuscript.}

\section{References}

1 Dravet C. Les épilepsies graves de l'enfant. Vie Med 1978; 8: 543-548.

2 Dravet C, Bureau M, Oguni H, Fukuyama Y, Cokar O. Severe myoclonic epilepsy in infancy: Dravet syndrome. Adv Neurol 2005; 95: 71-102.

3 Claes L, Del Favero J, Ceulemans J, Laga L, Van BroeckhovenC, De Jonghe $\mathrm{P}$. De novo mutations in the sodium channel gene SCN1A cause severe myoclonic epilepsy of infancy. Am J Hum Genet 2001; 68: 1327-1332.

4 Bernard G, Shevell M I. Channelopathies: a review. Pediat Neurol 2008; 38: 73-85.

Canale V C, Smith C H. Chronic lymphadenopathy simulating malignant lymphoma. J Pediat 1967; 70: 891-899.

6 Sneller M C, Wang J, Dale J K, Strober W, Middelton L A, Choi Y et al. Clinical immunologic and genetic features of an autoimmune lymphoproliferative syndrome associated with abnormal lymphocyte apoptosis. Blood 1997; 89: 1341-1348.

Sneller M C, Dale J K, Straus S E. Autoimmune lymphoproliferative syndrome. Curr Opin Rheumatol 2003; 15: 417-421.

8 Mulley J C, Scheffer I E, Petrou S, Dibbens L M, Berkovic S F, Harkin L A. SCN1A mutations and epilepsy. Hum Mutat 2005; 25: 535-542.

9 Mullen S A, Scheffer I E. Translational research in epilepsy genetics. Arch Neurol 2009; 66: 21-26.

10 Harkin L A, Mc Mahon J, Jona X, Dibbens L, Pelekanos J T, Zuberi S et al. The spectrum of SCN1A - related infantile epileptic encephalopathies. Brain 2007; 130: 843-852.

11 Mancardi M M, Striano P, Gennaro E, Madia F, Paradivino R, Scapolan $S$ et al. Familial occurrence of febrile seizures and epilepsy in severe myoclonic epilepsy on infancy (SMEI) patients with SCN1A mutations. Epilepsia 2006; 47: 1629-1635.

12 Lossin C. A catalog of SCN1A variants. Brain and Development 2009; 31: $114-130$.

13 Oakley J C, Kalume F, Yu F H, Scheuer T, Catterall W A. Temperature and age-dependent seizures in a mouse model of severe myoclonic epilepsy in infancy. PNAS 2009; 106: 3994-3999.

14 Catarino C B, Liujy W, Lïagouras I, Gibbons V S, Labrum R W, Ellis R et al. Dravet syndrome as epileptic encephalopathy: evidence from long-term course and neuropathology. Brain 2011; 134: 2982-3010.

15 Rhodes T H, Lossin C, Vanoye C G, Wang D W, George A L. Non inactivating voltage-gated sodium channels in severe myoclonic epilepsy of infancy. PNAS 2004; 101: 11.147-11.152 
16 Ravizza T, Gagliardi B, Noè F, Boer K, Aronica E, Vezzani A. Innate and adaptive immunity during epileptogenesis and spontaneous seizures: evidence from experimental models and human temporal lobe epilepsy. Neurobiol Dis 2008; 29: 142-160.

17 Vezzani A, Balosso S, Ravizza T. The role of cytokines in the pathophysiology of epilepsy. Brain Behav Immun 2008; 22: 797-803.

18 Heida J G, Pittman Q. Causal links between brain cytokines and experimental febrile convulsions in rat. Epilepsia 2005; 46: 1906-1913.

19 Fisher G H, Rosenberg F J, Straus S E, Dale J K, Middleton L A, Lin A $\mathrm{Y}$ et al. Dominant interfering FAS gene mutations impair apoptosis in a human autoimmune lymphoproliferative syndrome. Cell 1995; 81: 935-946.

20 Rieux-Laucat F, Le Deist F, Hivbroz C, Roberts I A G, Debatin K M, Fisher A, De Villartay J P. Mutations in FAS associated with human lymphoproliferative syndrome and autoimmunity. Science 1995; 268: 1347-1349.

${ }^{21}$ Bleesing J J, Brown M R, Straus S E, Dale J K, Siegel R M, Johnson M et al. Immunophenotypic profiles in families with autoimmune lymphoproliferative syndrome. Blood 2001; 98: 2466-2473.

22 Auricchio L, Vitiello L, Adriani M, Ferri P, Chiocchetti A, Pettinato G et al. Cutaneous manifestations as presenting sign of autoimmune lymphoproliferative syndrome in childhood. Dermatology 2005; 210: 336-340.

23 Worth A, Thrasher A J, Gaspar H B. Autoimmune lymphoproliferative syndrome: molecular basis of disease and clinical phenotype. British Journal Haematology 2006; 133: 124-140.

24 Wong C S, Arkwright P D, Rieux-Laucat F, Cant A J, Stevens R F, Judge M R. Childhood linear IgA disease in association with autoimmune lymphoproliferative syndrome. Brit J Dermatol 2004; 150: 578-580.

25 Wu J, Wilson J, He J, Xiang L, Schur P, Mountz J D. Fas ligand mutation in a patient with systemic lupus erithematosus and lymphoproliferative disease. J Clin Invest 1996; 98: 1107-1113.

26 Dianzani U, Bragardo D, Di FrancoD, Alliaudi C, Scagni P, Buonfiglio D et al. Deficiency of the FAS apoptosis pathway without Fas gene mutations in pediatric patients with autoimmunity/lymphoproliferation. Blood 1997; 89: 2871-2879.

27 Wang J, Zheng L, Lobito A, Chan F K, Dale J, Sneller M et al. Inherited human Caspase 10 mutations underlie defective lymphocyte and dendritic cell apoptosis in autoimmune lymphoproliferative syndrome type II. Cell 1999; 98: 47-58.

28 Chun H J, Zheng L, Ahmad M, Wang J, Speirs C K, Siegel R M et al. Pleiotropic defects in lymphocyte activation caused by Caspose- 8 mutations lead to human immunodeficiency. Nature 2002; 419: 395-399.

29 Ramenghi U, Bonissoni S, Migliaretti G, De Franco S, Botterei F, Gambaruto C, Di Franco D, Priori R, Conti F, Dianzani I, Valesini G, Merletti F, Dianzani U. Deficiency of the Fas apoptosis pathway without Fas gene mutations is a familial trait predisposing to development of autoimmune diseases and cancer. Blood 2000; 95: (10) 3176-3182.

30 Oliveira JB, Blesing JJ, Dianzani U, Fleischer TA, Jaffe ES, Lenardo MJ et al. Revised diagnostic criteria and classification for the ALPS: report from the 2009 International workshop. Blood 2010; 116: 35-40.

31 Dianzani U, Chiocchetti A, Ramenghi U. Role of inherited defects decreasing Fas function in autoimmunity. Life Sciences 2003; 72: 2803-2824.

32 Berio A, Piazzi A. A case of Kearns-Sayre syndrome with autoimmune thyroiditis and possible Hashimoto encephalopathy. Panminerva Med 2002; 44: 265-269.

33 Rieux-Laucat F, Magerus-Chatinet A. Autoimmune lymphoproliferative syndrome : a multifactor disorder. Haematologica 2010 ; 96 : (II) 1805-1807.

34 Chiocchetti A, Indelicato M, Bensi T, Mesturini R, Giordano M, Sametti S, Castelli L, Botterel F, Mazzarino MC, Gambarini L, Giacopelli F, Valsini
G, Santoro C, Dianzani I, Ramenghi U, Dianzani U. High level of osteopontin associated with polymorphism in its gene are a risk factor for development of autoimmunity/lymphoproliferation. Blood 2004 ; 104 : (4) 1376-1382.

35 Clementi R, Chiocchetti A, Cappellano G, Cerutti E, Ferretti M, Orilieri E, Dianzani I, Ferrarini M, Bregni M, Danesino C, Bozzi V, Putti MC, Cerutti F, Cometa A, Locatelli F, Maccario R, Ramenghi U, Dianzani U. Variations of the perforin gene in patients with autoimmunity/lymphoproliferation and defection. Blood 2006; 108 (9): 3079-3084.

36 Boggio E, Clemente N, Mondino A, Cappellano G, Orilieri E, Gigliotti C, Toth E, Ramenghi U, Dianzani U, Chiocchetti A.IL-17protects T cells from apoptosis and contributes to development of ALPS-like phenotypes. Blood 2014; 123 (8): 1178-1186.

37 Mesturini M, Gigliotti CL, Orlieri et al. Differential induction of IL-17, IL-10 and IL-9 in human T helper cells by B7h and B7.1. Cytokine 2013; 64: 322-330.

38 Clementi R, Dagna L, Dianzani U, Duprè L, Dianzani I, Ponzoni M, COmeta A, Chiocchetti A, SAbbadini MG, Rugarli C, Ciceri F, Maccario R, Locatelli F, Danesino C, Ferrarini M, Bregni M. Inherited perforin and Fas mutations. N Engl J Med 2004; 351: 1419-1424.

39 Aricò M. Boggio E, Cetica V, Melensi M, Orilieri E, Clemente N, Cappellano G, Buttini S, Soluri MF, Comi C, Dufour C, Pende D, Dianzani I, Ellis SR, Pagliano S, Marcenaro S, Ramenghi U, Chiocchetti A, Dianzani U. Variations of the UNC 13 D gene in patients with autoimmune lymphoproliferative. S.PLOS one 2013; 8-7 1-9 e 68045.

40 Ray RB, Meyer K, Steele R, Shrivastava A, Aggarwal BB, Ray R. Inhibition of tumor necrosis factor (TNF-a) mediated apoptosis by hepatitis $\mathrm{C}$ virus core protein. J Bioch Chem 1998; 273 (4): 2256-2259.

41 Choi C, Benvenista EM. Fas ligand/Fas system in the blood: regulator of immune and apoptotic responses. Brain Research Rev 2004; 44: 65-81.

42 Comi C, Fleetwood T, DIanzani U. The role of T cell apoptosis in nervous system autoimmunity. Autoimmunity Reviews 2012; 12: 150-156.

43 Shenoy S, Arnold S, Chatila T. Response to steroid therapy in autism secondary to autoimmune lymphoproliferative syndrome. J Pediat 2000; 136: 682-687.

44 Saas P, Walker PR, Hahne M, Quiquerez AL, Schnuriger V, Perrin G, French L, Van Meir EG, Tribolet (de) N, Tschopp J, Dietrich PY. Fas ligand expression by astrocytoma in vivo: maintaining immune privilege in the brain?. J Clin Invest 1997; 99 (6): 1173-1178.

45 Giordano C, Stassi G, De Maria R, Todaro M, Richiusa P, Papoff G, Ruberti G, Bagnasco M, Testi R, Galluzzo A. Potential involvement of Fas and its ligand in the pathogenesis of Hashimoto's thyroiditis. Science 1997; 275: 960-963.

46 De Maria R, Testi R. Fas-FasL interactions: a common pathogenetic mechanism in organ-specific autoimmunity. Immunology Today 1998; 19: 121-125.

47 Bona $G$, Defranes S, Chiocchetti A, Indelicato A, Biava A, Difranco D et. Al. Detective function of Fas in T cells from paediatric patients with autoimmune thyroid disease. Clin Exp Immunol 2003; 133: 430-437.

48 Thieben M J, Lennon V A, Boeve B K, Aksamit A J, Keegan M, Vernino $S$. potentially reversible autoimmune limbic encephalitis with neuronal potassium channel antibodies. Neurology 2004; 62: 1177-1182.

49 Forchetti C M, Katsamakis G, Garron D C. Autoimmune thyroiditis and a rapid progressive dementia. Neurology 1997; 49: 623-626.

50 Palace J, Lang B. Epilepsy: an autoimmune disease?. J Neurol Neurosurg Psychiatry 2000; 69: 711-714.

51 De Giorgio L A, Konstantinov K N, Lee SC, Hardin J A, Volpe B T, Diamond B. A subset of lupus anti-DNA antibodies cross reacts with the NR2 glutamate receptor in systemic lupus erithematosus. Nat Med 2001; 7: 1189-1193. 
52 Santoro M, Thomas F P, Fink M E, Lange D J et al. IgM deposits at nodes of Ranvier in a patient with amyotrophic Lateral Sclerosis, Anti GM1 antibodies and multifocal motor conduction block. Ann Neurol 1990; 28: 373-377.

53 Waxman S G. Sodium channel blockade by antibodies: a new mechanism of neurological disease? Ann Neurol 1995; 37: 421-422.

54 Vassilev P M, Scheuer T, Catterall W A. Identification of an intracellular peptide segment involved in sodium channel inactivation. Science 1988; 241: 1658-1661.

55 Karpiak S E, Huang Y Y, Rapport M M. Immunological model of epilepsy. J Neuro- immunol 1982; 3: 15-21.

56 Meiri H, Goren E, Bergmann H, Zeitoun I, Rosenthal Y, Palti Y. Specific modulation of sodium channels in mammalian nerve by monoclonal antibodies. Proc Natl Acad Sci USA 1986; 83: 8385-8389.

$57 \mathrm{Yu} \mathrm{F} \mathrm{H}$ et al. Reduced sodium current in GABA ergic interneurons in a mouse model of severe myoclonic epilepsy of infancy. Nat Neurosc 2006; 9: 1142-1149.
58 Suleiman J, Brenner T, Gill D, Brilot F, Antony J, Vincent A, Lang B, Dale R C. VGKC antibodies in pediatric encephalitis presenting with status epilepticus. Neurology 2011; 76: 1252-1255.

59 Mc Intosh A M, Mc Mahon J, Dibbens L M, Iona X, Mc Culley J C, Scheffer I, Berkovic S F. Effects of vaccination on onset and outcome of Dravet syndrome: a retrospective syudy. Lancet Neurol 2010; 9: 592-598.

60 Berkovic S F, Harkin L, Mc Mahon J, Pelekanos J T, Zuberi S M, Wirrell E C, Gill D S, Iona X, Mulley J C, Scheffer I E. De novo mutations of the sodium channel gene SCN1A in alleged vaccine encephalopathy: a retrospective study. Lancet Neurol 2006; 5: 488-492.

61 Connolly A M, Chez M G, Pestronk A, Arnold S T, Mehta S, Deuel R K. Serum antibodies to brain in Landau-Kleffner variant, autism and other neurological diseases. [Connodly AM].... J Ped 1999; 134: 607-613

62 Wong-Kisiel L C, Mc Keon A, Wirrell E. Autoimmune encephalopathies and epilepsies in childen and teenagers. Can J Neurol Sci 2012; 39: 134-144.

63 Tan K M, Lennon V A, Klein C J, Boeve B T, Pittock S J. Clinical spectrum of voltage-gated potassium channel autoimmunity. Neurology 2008; 70 : 1883-1890. 